\title{
Mathematics Teaching Reform Study in Higher Vocational College Based on Vocational Capacity Needs
}

\author{
Shao Feifei \\ Liao Ning Urban Construction Technical College, \\ ShenYang, Liaoning, 110122
}

\begin{abstract}
Modern society needs people with vocational ability and higher vocational colleges also aim at cultivating students with high professional competence. Many people think that mathematics teaching in vocational colleges is irrelevant with professional competence training, but the author thinks that mathematics teaching in vocational colleges is essential to enhance students' professional ability, even crucial. Starting from the cultivation of students' professional ability, the author combines the mathematics teaching reform with professional ability.
\end{abstract}

Keywords- mathematics teaching reform; professional ability; docking study

\section{INTRODUCTION}

Currently, many vocational colleges in our province increasingly do not pay attention to the basic course, repeatedly reducing the course, several specialties has even advanced mathematics courses canceled. As an important foundation subjects, which way the mathematics in the end is supposed to follow. As a mathematics teacher in vocational schools, in the author's opinion, mathematics reform in higher vocational college is imminent.

\subsection{Fixed curriculum standard}

According to discussion on mathematics teaching with several other universities, the author found that vocational colleges get used to using curriculum standards which is just slightly modified on undergraduate university curriculum standards. Characteristics of undergraduate university curriculum standards are comprehensive, rich in knowledge points and complex, but higher mathematics is a learning courses based on elementary mathematics and has strict requirements on students' mathematical basis. Furthermore, undergraduate math class is on Saturday and has 12 credits in the first and second half of semester. But in vocational colleges the math class is on Tuesday and has only 4 credits, what's more, students in vocational schools is at varying levels of mathematics and are generally poor at mathematics. With continuous reform of Chinese education system, continuous enrollment increase and appearance of colleges, vocational schools are not very optimistic in terms of quality and quantity of students, so that teachers feel that students is not as good as last session. So the first step for higher mathematics course reform is to enact mathematics curriculum standards suitable for vocational colleges. Only curriculum standards suitable for vocational colleges can make math curriculum standards advance and get better 
development.

\subsection{Highly difficult mathematics teaching material}

In the past five years, many vocational colleges have chosen textbooks published by higher education press. These textbooks are compiled by prestigious university professors with comprehensive and systematic teaching contents. What is different to undergraduate textbook is that after-class exercises is much simpler. While in vocational colleges trial process of textbooks, the author found a lot of problems. For example, for vocational students, question which is quite simple for undergraduate students is still difficult. Because of poor foundation, many students is in loss of confidence for mathematics and is not interested in learning. So authoritative teaching materials can not make mathematics teaching becomes interesting. The only way is that mathematics teacher in vocational colleges think over by themselves how to break the original mathematical system and establish new mathematical system suitable for students in vocational colleges to learn.

\subsection{Traditional teaching method}

The traditional way of teaching is that teachers at the podium keep on speaking while students in their seats listen. In order to complete the task of teaching, sometimes teachers will not leave extra time for students to think and ask questions. When a class is over, the teacher is rather tired and students are also tired and as a result can not get satisfactory test results. This teacher-centered teaching method can no longer adapt to current society. With the full coverage of the campus network, students all have a smart phone installed with Wechat, QQ and interesting game. Compared with boring math teaching, students are more likely to be attracted by these funny games, even too indulged to extricate themselves. So teachers can not blindly use traditional teaching methods to teach, they should find new ways to teach so that mathematics can obtain sustainable development.

\section{Analysis of vocational competence}

Professional competence may include three main elements: the first one is ability required by a particular profession. The students learn in school for the purpose of engaging in a particular occupation. What they learn in school is the theoretical basis which can guide practice through internships at work theory. Students accumulate experience at work and get promotion from assistant to engineer, and even a senior engineer. Strong professional competence is needed in the process. The second one is occupational ability presented at work. Professional quality presented by students at work is more important, whether love work and dedicated or not, whether they can spare no efforts and innovative or not, whether they have a strong sense of responsibility and mission or not; whether they have good communication skills and a good sense of teamwork or not; whether they can place themselves, continue to learn and progress, and finally create a good charisma or not. The third one is career management skills after the start of career. Students should make a detailed career plans, namely the long-term goals and short-term goals. If there is no goal, they have no direction and motivation at work which can lead to muddling along at work. Day after day, they will lose the passion of work as well as the chance of promotion. On the other hand, the company will think that such workers do not create higher value, and you will be dismissed. Therefore, 
only vocational colleges train students with good vocational ability can they cultivate high-quality talents for the community and the country.

\section{Docking study on mathematics teaching} reform and professional ability

\subsection{Set advanced mathematics curriculum} standards suitable for vocational schools

For the problems that vocational college has less math class, students are poor at mathematics and the contents of higher mathematics involved are comprehensive and complex, first of all, the author examine what students have learned at high school, for example, limits, derivatives, definite integral etc. Moreover, the author analyzes the degree of difficulty of high school mathematics. Secondly, together with specialty teachers, we discuss the mathematics knowledge needed in professional course and degree of difficulty required. Finally, starting with easy and interesting learning and based on the principle of necessity and sufficiency, the author develops a new curriculum standard. It covers fundamental part of higher mathematics, derivative and differential, indefinite integral and the definite integral, calculus of micro simple binary function, adding engineering mathematics linear algebra, probability and statistics.

\subsection{Compile Higher Vocational Schools' Materials meeting specialty requirements}

With the new math curriculum standards, through research, the author arranges mathematics contents involved in various specialized courses, summarize mathematics knowledge points required in professional course and finally compile textbooks by the joint efforts of all teachers in the Department of Mathematics. In the teaching materials, redefine the abstract and difficult mathematical definition in plain language and fill in the new definition with interesting mathematical problems in life by searching information so that students enjoy learning and learn more. For example, at class of limits of function, I first asked everyone a very interesting math question:" which is small between 0 and 1 ," and thus can teach students concept of limits by comparing two numbers. On the selection of textbook example, the first should be closely integrated with mathematical knowledge, both simple and representative. The second is to combine students' professional courses so that students will use mathematical knowledge learned in professional class to solve professional problems. That is to say mathematics courses lay the foundation for professional courses which fully reflects a notable feature that basic course serves for professional course. On textbook exercises, selected exercises can be divided into two groups of A and B. A is a group of simple questions aiming at highlight knowledge mainly suitable for all students .Group B are optional exercises for students who have better mathematical foundation and at the same time can lay the foundation for individual students who participate in the entrance examination of top-up. Finally, in order to increase students' mathematics interest in learning, exercises can be placed before the history of mathematics or some stories of mathematician.

\subsection{Various teaching methods such as task-driven approach}

Take a task-driven teaching methods: in the classroom, the students are the leading actor and teachers are director. Teachers assign tasks before class, so that students will gather in small groups and each group will corporate. to solve 
the problem. According to the completion of each group, teachers give guidance and evaluation. In the learning process, students not only give full play to the initiative and desire to learn, but also their skills to analyze and solve problems, logic skills, computing skills of completing tasks, communication skills and team working have been greatly improved. The author know that when students step into the society after graduation, they may only use simple elementary mathematical knowledge in work and life, but in my classroom, what I want to teach students is not just advanced mathematics, but the process of learning.

\subsection{Cultivation and further study of teachers}

In the new century, teachers is to keep learning to keep pace with the times. Whether professional skill, the teaching methods, teaching skills or ethics training and other aspects, teachers should advance with times and keep continuous learning to be good teachers respected and welcomed by students.

\section{Conclusion}

In higher vocational colleges, as a basic course, mathematics gives students not only knowledge, but also professional quality and professional competence. The capacity cultivation comes little by little and is subtle. At the class after the reform of mathematics teaching, the students' computing ability, logical ability, skills to identify and solve problems, communication skills and teamwork would be comprehensively improved. Meanwhile, the author will continue to carry out research on this subject to explore better ways of educating people and cultivate more excellent talents for the country.

\section{Acknowledgment}

[Fund] Education science five-year plan of Lliaoning province, grant No.:JG14EB110, document No.89 issued in 2014 by Liaoning Education Department

\section{References}

[1] Hong Liying, Exploration on task-driven advanced mathematics teaching reform based on the integration of talent training mode, Journal of Beijing industrial vocational and technical college, 2015(01)

[2] Gong Xiaofeng, Students' comprehensive vocational ability training research in higher vocational college at enrollment expansion times, East China Institute of Technology, 2013

[3] $\mathrm{Xu} \mathrm{Su}, \mathrm{Wu}$ Fei, Professional ability and effective way to cultivate, vocational and technical education, 2012(10)

[4] Shi Yong, necessity of meeting professional needs on advanced mathematics course and teaching exploration, Shandong Normal University, 2011

[5] Gao Haiyan, Introduction to advanced mathematics teaching reform, electronic production, 2015(04) 